\title{
Correction to: Composition, Formation, and Occurrence of Polymetallic Nodules
}

\author{
T. Kuhn, A. Wegorzewski, C. Rühlemann, and A. Vink
}

\section{Correction to:}

Chapter 2 in: R. Sharma (ed.), Deep-Sea Mining, https://doi.org/10.1007/978-3-319-52557-0_2

This chapter was inadvertently published with error.

On pages 44-45 in Equations $2.1-2.4$ the formula for ammonia is wrong. It must read $\mathrm{NH}_{3}$ instead of $\mathrm{HN}_{3}$. In Table 2.1 the data for the $\mathrm{Ce}$ anomaly got lost somehow (last line of the table). The original chapter has been updated with these corrections. 